\title{
Narrative Strategies of Documentary in New Media Era
}

\section{Zhao Weiliang}

Institute of Media, BaiCheng Normal University, Baicheng, 137000, China

13769461@qq.com

Keywords: new media era; documentary; development and change; narrative strategy

\begin{abstract}
Documentary is a kind of based on the life, has the unique art form of literature value. In the record social change and heritage human civilization plays an irreplaceable role. The emergence of new media, increase the spread of documentary channel. Makes the transmission speed faster, broader and more influential. Creators also want to adapt to the times development, the traditional narrative strategy adjustment, develop the creative concept and keep the documentary high-end character. Combined with the characteristics of new media, this paper put forward the new media era of documentary narrative strategies as follows: individual narrative combines with fragments of narrative, sorts out the background of the story and history change, plays the fusion of art and modern audio-visual language, strengthens the result of technology aesthetics outstanding film and builds psychological identity through emotional close.
\end{abstract}

\section{Introduction}

Documentary is based on real life creative material to the true story for performance object, and carries on the artistic processing and presentation, in order to show true nature, and real cause people to think about a movie or television art form. Documentary in different social morphology and the historical period has a different expression techniques and creative way. New media is compared with the traditional media, traditional media such as newspaper, radio, television after the development of new media forms, is the use of digital technology, network technology and mobile technology, through the Internet, wireless communication network, cable network and channels such as computers, mobile phones, digital TV and other terminal, to provide customers with the spread of information and entertainment form and media form. The emergence of new media, increase the spread of documentary channel, television and video web sites provides documentary broadcast platform, more people can see and understand the documentary. Documentary to spread faster, broader and more influential.

The new media era, the documentary what to say and how to say, is always the most important. People can use mobile phones, cameras and spread of things of interest. In the face of numerous information, people can choose on their own, no longer just passive acceptance, content and expression of the theme of the documentary requirements is higher. Documentary creation only care about the needs of the audience, close to their lives, says they care about, to attract their attention. Different media era, everyone has a voice, can express their ideas, audiences are no longer satisfied with passive to accept. They "content production to participate in the discourse right, information selection for, to share, transmission control to break". Medium for the spread of modern media is not only, also is the communication and interaction between communicators and audience's platform. Play to the characteristics of new media interaction and two-way communication, let more people involved in the film, a documentary will contain more further information about the times and more vivid details of life.

\section{Development and Change of Chinese Documentary}

Relative to the development history of foreign documentary, documentary film creation and research in China are in arrears. Documentary in the $1950 \mathrm{~s}$, China news documentary is in strong political color. Since the reform and opening up, the social transformation in China, the artistic atmosphere from closed to open gradually. Documentary creation also broke through the original 
imprison, political indifference, gradually began to appear in a batch of excellent documentary. The development process can be divided into three stages:

The first stage, the political philosophy of desalination and national consciousness. After the reform and opening to the outside world, the cultural collision and communication, accelerated the awakening of national consciousness, people begin to shift perspective, emancipate the mind, to find and think about life meaning and cultural roots. Documentary also by radical propaganda into a celebration of the motherland great rivers, and the call of the national spirit, has the national spirit symbol thing in the world of the subjects in the sights of China documentary. A group of outstanding cultural documentaries appeared in front of people, ushered in the reform and opening up after the first peak of documentary in our country. This period of China's TV documentaries, take the macro narrative technique, abandoned the personality cult, with the help of good country side show to the motherland, condenses the national spirit, aroused the people's national centripetal force, strengthen the participation of the audience.

The second stage, a variety of subjects attempt and the awakening of public communication. Tide of economic development in the $1990 \mathrm{~s}$ shocks every ordinary people, people's thought and survival state, a great change fate began more and more attention to individual life and ordinary people. Period of work, full of expression for individual and independent personality. With the speeding up of the democratic process and the gradual improvement of the social transparency, people self-consciousness awakening, the pursuit of truth, and the attention to human society, as well as to the expression of personality, begin to gradually in documentary production, the content of television documentaries and shooting Angle also began to present diversity. The $90 \mathrm{~s}$ television documentary, personal attention to replace the group to explore, filming technology is also risen to a new height. Images are more realistic.

The third stage, multi-cultural blends with the boutique creative consciousness. The 21st century is the era of human culture to cope with each other and to the integration, is also a variety of multivariate rendezvous and the era of the sharp collision between cultures. As the thinking mode transformation and the impact of postmodernism, subjective increasingly development and performance of the concept in the documentary, stories and drama more prominent, the Chinese television documentary creation form has entered a new era of diversity. Lost appeal the most traditional way of story, the Chinese documentary feature has been applied to reference in exploring the way of creation, in the form of a story about the people and the things of the documentary. Criticism of society shows a more rational thinking, beyond the narrow emotional psychology, more the pursuit of objective thinking and humanistic care, and respect for life.

\section{Characteristics of New Media}

The characteristics of the new media interaction and immediacy, mass and participatory, multimedia and hypertext, individual and community.

(1) Interactive and real-time. The spread of traditional media is a one-way, line and chooses. The spread of new media is a two-way, traditional publishers and audiences have been the publisher of information, but also can interact. interactive information also makes the audience realized the change from passive to active. The development of the technology that modern media can realize real-time transmission, simple convenient that information technology can be realized in the global real-time transmission. This advantage is unmatched by any traditional media.

(2) Mass and participatory. Huge amounts of sex can be understood from the following aspects. The network transmission to realize the global coverage; network communication has realized the mass storage of information; the information stored in the network transmission of diversity. The internet connects the world of computers and computer. Thus forming a huge database. Traditional media often confined to the limited transmission range, and the network transmission is not subject to regional restrictions, in every corner of the world, as long as have the conditions to get information on the Internet.

(3) Multimedia and hypertext. Network communication is to achieve the "text, sound, images, and animation" the combination of a variety of means such as multimedia communication, and 
maximize the spread of various forms of " combination", enrich the transmission methods. Text constitute mode of hypertext and the spread of the hyperlink structure that makes possible the time and space of information retrieval, all-around opening up easily realized "at this point or at the time", " here or there", " time together or not", "synchronous or asynchronous" query functions.

(4) Individual and community. Personal characteristics of network transmission is very obvious, the benefits of such technology can make the audience easy to use various retrieval tools in all kinds of database " everybody picks up his things", "information push technology" can also be based on user demand for information push service specialization. Is equivalent to free provides a virtual network community communication space. Make people have a common demand can easily and has no time to have discussion space information space and freedom.

\section{Narrative Strategies of Documentary in New Media Era}

With the continuous development of new media, inclusive for information from the Internet will continue to strengthen, the audience's demand will also gradually differentiation, and the forms of documentary will satisfy the needs of the different cultural taste, present a narrative strategy of diversified forms. Combined with the related research cost, this paper put forward by the new media era of documentary narrative strategies as follows:

(1) Individual narrative combined with fragments of the narrative. Today the life of people is full of the content of the fragmentation segmentation, in after entering the Internet age, information dissemination fragmentation has gradually become a vivid description of the social communication context. Fragments are considered to be two aspects: first is the fragmentation of information content. In the vast intricate network media information, despite the different web sites for the same and related information to comb, but still scattered throughout the network information content, unless special arrangement and classification, or the spread of the information is fragmented. This is mainly based on the new technology for the public lifestyle change, followed by the audience fragmentation in social lifetime, to adapt to conform to the characteristics of the new media. Traditional documentary grand narrative strategy, show the subjective didactic dense and not the characteristics of the ground, the effectiveness of narrative, narrative style by the audience. The new media era, as a supplement to the grand narrative, individual narrative and fragmented narrative strategy of combining gets gradually the favor of the creator. It can meet the needs of the audience in the limited time.

(2) Clarify the time background and historical changes of the story. Telling a story is tantamount to depict characters, that truth, revealing with regularity. After planning for narrative, is not equal to the actor to play the real historical events or real people repeat real events. To keep the content on the basis of real, not in order of time space, enhance the dramatic factors, prominent contradiction. On the structure design, if in chronological order, the advantage is easy to understand, but the dramatic difference, diminished appeal; If the design in space order, good advantage is comparative, but conflict is not easy to reflect, suspense design is more difficult. Advice to determine a common thread, fully considering the related factors, put the details in a series into a story, makes the plot of the story the trunk, not affected by time and space constraints, bold use of flashbacks and interleave. Particular way is: the story should have rich knowledge, namely, sociology, history, political science, psychology, and natural science knowledge; Telling a story to have a keen insight; Stories about human nature and human feelings and the heart; Telling a story to boldly, cleverly setting suspense, and the best choice for open-ended; Story should pay attention to rhythm and rhythm.

(3) Fusion of dramatic art and modern audio-visual language. Drama is a comprehensive art, literature, art, performance, music and dance and so on a variety of art at an organic whole, the language, action, props and scene combination become performance means, through the co-creation writers, directors and actors, the contradictions in life, is very sharp and intense, concentrated, reproduced on the stage, the audience is like a witness events or experiences in the drama, to obtain specific vivid artistic feeling. In the process of historical documentary film creation, situation representation is one of the most dramatic effects and the performance of the most beautiful form. The use of drama, as well as the feature technique reference, help documentary on TV and news, 
variety, the fierce competition of TV programs, won the is owned by own a piece of heaven and earth. "From the representation of imagery and emotional evolution to plot and effective representation, scene representation visual and sound effects of innovation, focusing on the shaping of the characters. The poignant scene representation from the past to build, to show in the history of dramatic plot, widely absorbs various elements of dramatic art again, entertaining and audiovisual sensations.

(4) Strengthen the result of technology aesthetics highlights film. Technical aesthetics is the fusion of technology and aesthetics, is to apply the aesthetic technology and emerging in the field of modern science, is an indispensable part of the artistic creation. Technology is the scientific research achievements into production practice of the discipline; Aesthetics is the highest form of art research, is the creative law of art and aesthetic value of the highest paradigm. Technical aesthetics is a scientific research results into the ways, methods of art production practice and law embodies the aesthetic value. Science and technology, casting a new art form, to improve the entirely different aesthetic concept. The development of technology and equipment, has realized the audio-visual effects of shock and promote, make the audience into the situation in the audio-visual pleasure, to appreciate the works and taste better. Such as the use of high-definition cameras, using prospective deep lens, macro lens and high-definition pictures, guarantee the documentary footage of exquisite requirements. In today's consumer society, visual culture is a type of typical cultural forms. Documentary makers, only the pursuit of audio-visual, bold use of innovative technologies, new methods, continuous upgrading of the audio-visual effects of documentary, to explore and develop the documentary market. Technology aesthetics overturned many traditional concept of art. For art has brought many new forms and artistic concepts, and even new aesthetic thinking.

(5) Through the emotionally close to construct psychological identity. Agree with psychological effect refers to the people of events in terms of emotional and cognitive identity degree to convey meaning, impact of the incident, attitude and behavior. Psychological identity restricts the people's attitude and behavior to a particular event. Any kind of art, has been widely accepted and approved, if you want to just be in the audience to produce identity psychological effect, have a positive psychological identity, will have a positive communication effect. Including three aspects: one is that benign subject consciousness, subject consciousness including creator in the production process of the value standard, artistic accomplishment and aesthetic tendencies and personality grade, etc. Subject consciousness to should not overlook the potential role of documentary creation, mainly exist in the artistic conception in the art system process; Second, clever characters, the audience on peace and real people, feel inferior to the moving and warm, as if it is very close to the audience and very far away, also may be in the audience, may also be the audience themselves; Three is, tender feeling about character, character is not only refers to the quality and style of the literary or artistic works, more emphasis on a kind of taste. Warmth as a kind of taste, sentiment of the press close to, can form become recessive influence factors in constructing psychological identity.

\section{Conclusion}

Media development has experienced elite media, the mass media and personal media, respectively, represents the propagation of the advance of the agricultural era, industrial era and the information age. In the rapid development of Internet, new media has from the edge of the mainstream. Radio relative newspaper is the new media. Television broadcast is relatively new media, network TV is relatively new media. Form in the progress of science and technology, media are developing, from the media as you can see, in the process of the occurrence and development of new media is accompanied by the media in changing the occurrence and development. In the era of new media, the artists should be the Angle of creative documentaries to meet user demand, both contain the style length and content of thinking, also includes writing strategy and methods of thinking; It should integrate the documentary resources, strengthen the television and folk film institutions and cooperation of the individual, to strengthen the cooperation between domestic and foreign documentary, with world documentary; Make full use of new media marketing strategy, documentary mining brand advertising implanted documentary this business new way of thinking. 
With the east and west cultural exchanges have become more frequent and close, the Chinese and foreign documentary creator will have the opportunity to make more close cooperation and communication. On the documentary film narrative strategy is bound to be learn each other, and to some extent for fusion, inspire more narrative strategy.

\section{References}

[1] N. Tang, "The innovation of documentary narrative strategy in the whole media era," Modern Communication(Journal of Communication University of China), vol. 33, no. 2, pp. 102-105, 2011.

[2] J. Yan, "On the narrative strategy of micro documentary," New Media Research, vol. 2, no. 16, pp. 175-176, 2016.

[3] Sina blog, "New media practice," http://www.doc88.com/p-700862151684, 2016-9-10.

[4] H. L. Ren, "Research on the narrative strategy of local documentary," Journal of Lanzhou Institute of Education, vol. 62, no. 2, pp. 44-45, 2014.

[5] W. Z. Liao, "The Research of Narrative Strategy of Documentary Film Based on the Context of New Media," Master's degree of Shanghai Normal University, 2013.

[6] X. Q. Wang, "Research on the Narrative Strategy about the Television Documentary A bite of China," Master's degree of Liaoninbg University, 2013.

[7] X. H. Zheng, "The narrative strategy of contemporary historical documentary," News World, vol. 21, no. 9, pp. 164-165, 2009.

[8] Z. P. Fang, "On the aesthetic strategy of contemporary TV documentary narration," Journal of Changzhou Institute of Technology(Social Science Edition), vol. 34, no. 1, pp. 44-47, 2016.

[9] J. Hao, "The new media environment for Chinese documentary production," Master's degree of Henan University, 2014.

[10] H. Q. Fang, "History of Chinese journalism and communication," http://www.100xuexi.com/ziliao/26934.html, 2016-9-9. 